\title{
CONFLITOS AMBIENTAIS NA AMAZÔNIA BOLIVIANA: IIRSA E CIDOB
}

\section{Environmental Conflicts in Bolivian Amazon: IIRSA and CIDOB}

Msc. Maria Angela Comegna

Grupo de Pesquisa Geografia Política e Meio Ambiente do Departamento de Geografia da USP Cidade Universitária, Av. Lineu Pretes, 338-CEP 05508-080 São Paulo (SP), Brasil Tel.: (+ 55 11) 3091-3769 - macomegna@uol.com.br

\section{$a \propto \boldsymbol{a}_{a} a$}

\begin{abstract}
Resumo
Nesse trabalho será analisado o movimento indígena decorrente dos impactos ambientais ocasionados pela IIRSA - Iniciativa para a Integração da Infra-Estrutura Regional Sul-Americana e seu principal empreendimento, o Complexo Hidrelétrico do Rio Madeira, nas populações indígenas da Amazônia boliviana que se encontram organizadas em uma confederação: a CIDOB (Confederación de Pueblos Indígenas de Bolivia). Dessa forma, pretende-se oferecer elementos que possam tanto contribuir com estudos de modelos de gestão de conflitos socioambientais, quanto subsidiar futuras políticas de promoção do desenvolvimento sustentável regional.
\end{abstract}

Palavras-chave: IIRSA, conflitos socioambientais, Região Amazônica, Bolívia, CIDOB

\begin{abstract}
The indigenous movement derived from the environmental impacts caused by IIRSA - Initiatives for Integration of Regional Infrastructure in South America and its main enterprise, the project Madeira River Complex on the indigenous populations of the Bolivian Amazon, which are organized into a confederation: the CIDOB (Confederación de Pueblos Indígenas de Bolivia) will be analyzed. Thus, it is intended to offer elements that can not only contribute to studies of models of environmental social conflicts management but also subsidize future policies which promote sustainable regional development.
\end{abstract}

Key words: IIRSA, environmental social conflicts, Amazon Region, Bolivia, CIDOB.

\section{Resumen}

En este trabajo será analizado el movimiento indígena consecuencia de los impactos ambientales ocasionados pela IIRSA- Iniciativa para la Integración de la Infraestructura Sudamericana y su principal construcción el Complejo Hidroeléctrico Río Madeira, en las poblaciones indígenas de Amazonia boliviana que se encuentran organizadas en una confederación: CIDOB (Confederación de Pueblos Indígenas de Bolivia). Por esta manera, intentase ofrecer elementos que puedan tanto contribuir con los estudios del modelos de gestión de los conflictos socioambientales, cuanto subsidiar futuras políticas de promoción del desenvolvimiento sustentable.

Palabras clave: IIRSA, conflictos socioambientales, Región Amazónica, Bolivia, CIDOB.

\section{$a \propto \boldsymbol{Q}_{a a}$}




\section{INTRODUÇÃO}

Os conflitos socioambientais são cada vez mais frequentes nos países da América Latina, onde o atual processo de globalização é, ao mesmo tempo, gerador de desigualdades sociais e de "identidades de resistência", constituídas por atores que precisam construir formas de resistência e sobrevivência, "lutando por justiça social e cidadania num modelo que fortalece assimetrias" (JACOBI 2009, p.3).

Esse fato deve-se tanto às dinâmicas sociais e econômicas que dizem respeito aos recursos naturais, quanto à ausência de políticas estatais efetivas que objetivam implementar esquemas de gestão disponíveis para a regulação do uso e acesso dos recursos naturais.

Por isso, torna-se usual que o Estado se encontre sem recursos técnicos, administrativos e financeiros necessários para administrar conflitos em torno do uso dos recursos naturais nos quais existem, por exemplo, grandes assimetrias de poder.

Da mesma forma, o avanço das ações de desenvolvimento vai colocando desafios à gestão dos recursos na medida em que exerce pressão para seu uso, o que também pode gerar diferentes tipos de conflitos.

Além disso, o uso dos recursos naturais e os conflitos socioambientais são um cenário de importantes repercussões para o futuro das nossas sociedades devido às mudanças que promovem em termos dos sistemas ecológicos e das propostas de desenvolvimento social.

Os objetivos principais a serem alcançados seriam o acesso e uso de recursos naturais ou a necessidade de reconhecimento ou participação no processo de tomada de decisão sobre o acesso e uso dos recursos de um grupo social, podendo-se afirmar que a forma de compreensão do conflito leva às formas determinadas de manejo do mesmo.

Dentro deste contexto, o conceito de racionalidade ambiental de Enrique Leff, se apresenta como um novo paradigma de um desenvolvimento alternativo.

Segundo Leff, os movimentos ambientalistas em países pobres se apresentam como uma resposta à destruição da natureza, de suas formas de vida e de seus meios de produção, como afirma a seguir:

são movimentos desencadeados por conflitos sobre o acesso e o controle dos recursos; são movimentos pela reapropriação social da natureza vinculados a processos de democratização, à defesa de seus territórios, de suas identidades étnicas, de sua autonomia política e sua capacidade de autogerir suas formas de vida e seus estilos de desenvolvimento. (LEFF 2001, p. 111)

Para o autor, nas práticas de apropriação e transformação da natureza se confrontam e misturam diferentes racionalidades: a do tipo capitalista de uso dos recursos; a racionalidade ecológica das práticas produtivas e a dos estilos étnicos de uso da natureza.

Estes conflitos socioambientais encontram-se dentro do âmbito do interesse público devido à relevância de alguns temas como a conservação, o desenvolvimento e o uso dos recursos naturais.

Segundo Enrique Leff, "os atos de consciência e seus efeitos na organização social e na mobilização política são ambientais enquanto internalizam um determinado paradigma ambiental" (LEFF 2001, p. 107) que, "sem uma perspectiva teórica e metodológica no estudo dos movimentos ambientais, corre-se o risco de reduzir o campo de visibilidade aos grupos e organizações ecologistas, ou de perder de vista o caráter ambientalista dos movimentos que não se autodesignam como tais" (LEFF 2001, p. 107).

A racionalidade ambiental, segundo o autor, não é a expressão de uma lógica, mas o efeito de um conjunto de interesses e de práticas sociais que articulam ordens materiais diversas que dão sentido e organizam processos sociais através de certas regras, meios e fins socialmente construídos (LEFF, 2007). Desta forma, a categoria racionalidade ambiental se apresenta como social.

Essa racionalidade ambiental apresenta como condições ao estudo dos movimentos sociais, a análise da democracia como premissa das práticas do ambientalismo e do efeito democratizante 
dos movimentos ambientalistas; a análise do impacto do discurso ambientalista (objetivos, valores e práticas) no discurso político e nas políticas econômicas, na ressignificação das demandas e reivindicações dos grupos sociais, bem como o desvendamento das estratégias de poder destes movimentos da sociedade civil para transformar a racionalidade dominante, incorporando os valores éticos e princípios produtivos do ambientalismo, além da observação da internalização dos princípios do ambientalismo nos direitos culturais emergentes e na perspectiva de um desenvolvimento nacional multiétnico (LEFF 2001, p.107-108).

As identidades coletivas locais passam assim a constituir um dos discursos nos quais se expressam esses conflitos (MARTÍNEZ ALIER 2007, p.344).

$\mathrm{E}$, apesar de cada grupo social ter uma forma de relação e apropriação dos recursos naturais, devido a aspectos culturais e as concepções sobre as formas de uso e aproveitamento dos recursos serem diferentes, determinando ações diferenciadas frente ao ambiente, movimentos sociais ou indígenas, podem melhorar suas demandas imediatas, por meio da incorporação de uma consciência ambiental, que incide sobre decisões mais complexas, como por exemplo, os padrões de uso de seus recursos (LEFF, 2007).

O entendimento da atuação da CIDOB- Confederación de Pueblos Indígenas de Bolivia, frente aos impactos socioambientais ocasionados pela IIRSA (Iniciativa para a Integração da Infra-Estrutura Regional Sul-Americana) nas populações indígenas da Amazônia boliviana pretende fornecer elementos para a análise da formação e da atuação de movimentos sociais frente à questão ambiental e sua influência sobre práticas sociais relacionadas à conservação e sustentabilidade no uso de recursos naturais, e para o entendimento da construção de estratégias de resistência à IIRSA, esta forma de articulação entre poder e território, geradas pelos movimentos sociais surgidos a partir de conflitos ambientais.

Assim, repensar as formas de governabilidade e as crises decorrentes que estão em andamento a partir deste processo de integração, é uma das justificativas para este trabalho.

\section{A IIRSA E O COMPLEXO HIDRELÉTRICO RIO MADEIRA}

Concebida dentro dos princípios do regionalismo aberto, a IIRSA foi criada no ano $2000 \mathrm{em}$ Brasília (Brasil) por 12 países sul-americanos, representados pelos seus respectivos presidentes (só a Guiana Francesa não aderiu), através de projeto apresentado pelo Banco Interamericano de Desenvolvimento (BID). Desde a sua criação, a IIRSA contemplou uma série de princípios orientadores em que se concentra um maior nível de troca qualitativa das relações internacionais através da integração físico-regional (McELHINNY, 2008).

A IIRSA é um acordo cujo objetivo principal é facilitar as vias de comunicação entre os países membros, um projeto de infra-estrutura que visa o desenvolvimento de canais de exportação dos recursos naturais, notadamente da Região Amazônica para fora e inter-relacionados a outros projetos de integração, que buscam essencialmente liberalizar o comércio e a inversão (URUGUAY SUSTENTABLE-REDES 2006).

A Iniciativa pretende, através de dez eixos de integração, chamados EIDs, traçar novas rotas adequada à geografia econômica do século atual. Esses eixos são: Andino, Escudo das Guianas, Amazonas, Peru-Brasil-Bolívia, Interoceânico Central, Capricórnio, Mercosul-Chile, Sul, Hidrovia Paraguai-Paraná e Sul Andino.

Desta forma, a Região Amazônica torna-se o centro do continente, mesmo não sendo a parte do continente onde passam os fluxos mais densos, localizados ao sul (THERY, 2005).

O Eixo do Brasil-Peru-Bolívia é considerado um dos principais da Iniciativa não só devido ao seu caráter estratégico, mas também devido às potencialidades e riquezas naturais da região, considerando a Amazônia uma região de importância primordial no desenvolvimento dos processos de integração física, das comunicações e da energia, que permitirão aproximar os mercados intra- 
-amazônicos, tratando-se de uma nova escala para pensar e agir na região (IIRSA 2009; CECENÃ e MOTTO 2007; BECKER 2005).

Este Eixo é composto por três grupos de projetos. O Grupo 1 é o Corredor Porto Velho-Rio Branco-Porto Maldonado-Cusco/Juliaca-Portos marítimos do Pacífico. O Grupo 2 é o Corredor Norte La Paz- Guajará-Mirim-Cobija- Rio-Branco. O Grupo 3 é o Corredor de integração fluvial impulsionado pela construção de centrais hidrelétricas e eclusas ao longo do Rio Madeira (Complexo Hidrelétrico do Rio Madeira).

O Complexo Hidrelétrico do Rio Madeira é o maior projeto hidroenergético da Região Amazônica, pois ele engloba o Rio Madeira, segundo rio mais caudaloso depois do Rio Amazonas.

As construções das represas do Rio Madeira vêm somar-se ao processo de destruição que há décadas está em andamento na Amazônia.

Esse projeto é composto de quatro hidrelétricas, sendo duas delas localizadas em Rondônia, no Brasil, próximas à fronteira com a Bolívia: são elas as usinas de Santo Antônio e Jirau, em fase de construção, que somariam juntas cerca de $6450 \mathrm{mw}$ de potência instalada (IIRSA, 2009). A outra represa se localiza em território boliviano, Cachuela Esperanza, e se encontra em fase avançada de estudo.

A represa de Guajará-Mirim, localizada em águas binacionais Brasil-Bolívia, se encontra em fase de estudos iniciais (IIRSA, 2009).

Porém, o projeto em si considera apenas as hidrelétricas de Santo Antônio, com localização a $5 \mathrm{~km}$ rio acima do centro de Porto Velho, a capital de Rondônia, com mais de 270 mil habitantes na área urbana, e a de Jirau, $136 \mathrm{~km}$ rio acima; juntas, com previsão de inundação de uma área de $529 \mathrm{~km} 2$ (IIRSA, 2009, AMIGOS DA TERRA-ECOA, 2007).

Assim, com essas obras, rios, populações e regiões inteiras poderão ser entregues às grandes empresas, em nome de um desenvolvimento cujos custos e benefícios não têm sido ainda corretamente mensurados (VERDUM 2007), embora atualmente exista "uma nova consciência quanto aos riscos das represas" (MARTÍNEZ ALIER 2007, p. 181).

Dentre os muitos riscos, ainda destacam-se na Região "a diminuição de estoques pesqueiros, novas enfermidades, emissões de metano, degradação da qualidade da água (...), rarefação da biodiversidade fluvial (...) e, por fim, os riscos oriundos dos colapsos das barragens" (MARTÍNEZ ALIER 2007, p. 181). E como o fluxo de água e a maior parte dos impactos não obedecem às fronteiras internacionais, existe o risco de que esses impactos afetem o Peru e a Bolívia (FOBOMADE, 2010).

Com essas obras, se pretende consolidar a ocupação da Amazônia. Desta maneira, verificam-se que as Políticas Púbicas Territoriais aplicadas na Amazônia são caracterizadas pela implementação de grandes obras de infra-estrutura, integrantes dos planos estratégicos nacionais.

O roubo dos recursos naturais, o genocídio e o etnocídio de povos indígenas amazônicos sempre se conjugaram na selva amazônica (CINGOLANI, 2010). Na região do Alto Rio Madeira este processo tem como uma das características principais a apropriação dos recursos naturais, transformações na organização social e na configuração territorial, devido à renovação da materialidade técnica do território, gerando um novo fluxo e refluxo na população da Região, que tem como consequência a instabilidade social, ambiental e econômica (CAVALCANTE, 2008).

A população local, que geralmente se encontra em precárias condições econômicas e sociais, é frequentemente levada a acreditar que essas grandes obras de infra-estrutura trarão perspectivas de melhorias e possibilidades de emprego, facilitando, portanto, a implantação dessas obras de gigantesco impacto, resultando em decisões não sustentáveis para essas populações (CAVALCANTE, 2008).

Segundo Paz (2006), ao final das obras, parte deste investimento público e privado passará a ficar ocioso, gerando um novo período de adaptação social e econômica.

Ainda segundo a autora, a finalização da obra da usina geralmente cria um vazio na economia regional, devido à redução de empregos, ou ainda o "aumento da migração para outras obras e em busca de oportunidades não oferecidas localmente, entre outros problemas (PAZ 2006, p. 51).” 
As áreas protegidas nos limites das áreas de influência direta e indireta das represas, tanto Terras Indígenas, como Unidades de Conservação e suas áreas limítrofes, apesar de sua denominação, apresentam um alto grau de vulnerabilidade, principalmente em relação ao aumento da atividade madeireira e ao avanço do desmatamento.

Neste sentido, o incremento significativo da população em consequência da mobilização da mão-de-obra e a migração associada, implicarão na abertura de novas fontes de ocupação, favorecendo a degradação ambiental do entorno das Terras Indígenas e a prática de atividades ilegais de atividades como a extração mineral e madeireira.

O aumento do número de empresas ligadas ao setor madeireiro e minerador da Região do Complexo, em função da diminuição do custo e aumento da oportunidade para sua instalação, como energia mais barata, mais estradas e hidrovias proporcionará ainda um incentivo da pressão sobre a floresta e Terras Indígenas, situadas nas áreas de influência dos empreendimentos, bem como aumento da contaminação na área.

Em virtude da antiga atividade garimpeira na Região, o leito do Madeira, rio acima das barragens previstas, já se encontra muito poluído com mercúrio.

O mercúrio poderá, devido a qualquer atividade de impacto no local, se infiltrar nos lençóis freáticos que abastecem parte da população, além de contaminar toda uma diversidade de peixes que são a base da alimentação da população ribeirinha e urbana, conforme afirma o estudo publicado pelo Bank Information Center (BANK INFORMATION CENTER-BIC, 2009).

Ainda como consequência imediata da intensa migração para a região pode-se destacar o aumento da demanda por habitações; o acúmulo de resíduos sólidos; pressões sobre o mercado imobiliário e as áreas de assentamentos; o aumento da demanda por serviços públicos de saúde, saneamento, educação, transporte público e segurança pública.

Desta forma, cabe perguntar, como Enrique Leff, "quanto poderia valer a saúde de pessoas que vivem fora das redes de mercado, como trabalhadores rurais e os indígenas, e que, não obstante, são afetados pelas condições de insalubridade e contaminação provocadas pelos projetos de desenvolvimento econômico?" (2001, p. 320).

Além disso, "as tentativas de ocupação legal e ilegal empreendidas pelos diversos atores presentes na região se fazem sentir com mais vigor nas terras indígenas, o que só contribui para agravar os conflitos atuais e futuros com o setor elétrico, na medida em que estes podem somar-se aos já existentes, produzindo conflitos ainda maiores". (PAZ 2006, p.15)

Assim, verificam-se áreas frágeis que acumulam passivos, conflitos de convivência entre a população local, população indígena e os migrantes; rupturas de comunidades locais; surgimento de novas localidades sem a adequada infra-estrutura; aumento da prostituição e da violência, entre outras consequências.

Haverá ainda um grande risco de epidemias de malária, dengue, febre amarela, enfermidades diarréicas, parasitoses, esquistossomose e outros quadros patológicos provocados pelo represamento das águas na região do Complexo. A esse fato, soma-se a debilidade dos sistemas de saúde da Região, que colocam a Bolívia entre aqueles de menor cobertura de serviços frente às modificações ambientais da magnitude das represas a serem construídas, causando impactos de grandes proporções à saúde da população boliviana que vive ao longo dos Rios Madeira e Mamoré.

Existem ainda os impactos oriundos da inundação sobre a região da floresta produtora de castanha, ou seja, da onde a população local obtém seu sustento e os recursos fitogenéticos com os quais produzem remédios utilizados pela sua medicina tradicional.

Desta forma, as hidrelétricas do Rio Madeira constituem-se em um novo elemento estrutural, gerador de novos arranjos, evidenciando o político e o poder de uso no território, "resultando em conflitos entre os agentes atuantes e mudanças no ordenamento territorial, dando-lhes características vinculadas a multidimensionalidade das escalas geográficas de objetivação social." (CAVALCANTE 2008, p.9) 
A construção das hidrelétricas no Rio Madeira adicionará novas relações sociais e econômicas ao território amazônico, onde os rios constituíram-se nas primeiras redes geográficas de transportes, influenciando no ordenamento territorial da Região.

\section{A CIDOB E O MOVIMENTO INDÍGENA NA BOLÍVIA}

A CIDOB (Confederación de Pueblos Indígenas de Bolivia), uma Organização Não-Governamental (ONG) fundada em 1982 em Santa Cruz de la Sierra, é a representante nacional do movimento indígena na Bolívia.

$\mathrm{Na}$ ocasião da sua fundação, houve a participação de representantes dos seguintes povos indígenas do Oriente boliviano: Guaraní-izoceños, Chiquitanos, Ayoreos e Guarayos.

Posteriormente em 1998, a CIDOB já contava com a participação de 34 povos indígenas, habitantes de todos os Departamentos da Bolívia, reunidos em organizações regionais (CPIB: Central De Pueblos Indígenas del Beni; CIRABO: Central Indígena de la Región Amazónica; CPESC: Coordinadora de Pueblos Étnicos de Santa Cruz; APG: Asamblea del Pueblo Guaraní; ORCAWETA: Organización de Capitanías Weehnayek; CPILAP: Central de Pueblos Indígenas de La Paz, CPITCO: Central de Pueblos Indígenas del Trópico Cochabamba e CIPOAP: Central Indígena de Pueblos Originarios de la Amazonía de Pando).

Segundo a geógrafa Luciana Ziglio, "as Organizações Não-Governamentais (ONGs) são formas jurídicas institucionalizadas, mantidas pelo setor privado ou público, com participação da sociedade que se organizam em torno dos chamados direitos sociais como, por exemplo, a preservação do meio ambiente" (2008, p.1).

A autora afirma que "as ONGs dedicadas às temáticas ambientais têm como objetivo central a afirmação de uma alternativa viável de conservação ou de restauração do ambiente danificado" (ZIGLIO 2008, p.1), sendo que uma forma de inserção nas sociedades é a busca da preservação ambiental ou da participação social na preservação ambiental.

No caso da CIDOB, pode-se afirmar que a organização é reconhecidamente um movimento popular que estabelece relações institucionais com diversas instâncias do Estado "a nivel nacional, con gobiernos locales con organizaciones populares nacionales e internacionales, con organizaciones públicas o privadas del desarrollo y cooperación" (CIDOB, 2010), cabendo ressaltar que a CIDOB é uma organização que não posuiu filiação política ou religiosa.

Dentre seus atuais projetos, podemos citar como um dos principais o Centro de Planejamento e Gestão Territorial Indígena, que tem como objetivos principais o aumento da participação da população indígena no desenvolvimento econômico e político, "así como dentro de las instituciones públicas relevantes en los ámbitos nacional y local, a fin de promover los derechos indígenas, identidad cultural y un desarrollo sostenible para los pueblos indígenas" (CIDOB 2010, p. 1).

O desenvolvimento sustentável, que tem por objetivo a qualidade de vida e depende da qualidade do ambiente para alcançar um desenvolvimento equilibrado, é aquele onde a qualidade de vida está vinculada a diversas formas de identidade e de cooperação, além das formas de "solidariedade, de participação e de realização, que entrelaçam a satisfação de necessidades e aspirações derivadas do consumo com diferentes formas de realização, através de processos de trabalho, de funções criativas e de atividades recreativas" (LEFF 2001, p. 324).

Assim, os povos indígenas das terras altas ou baixas da Bolívia devem participar no ordenamento e titulação de suas Terras Comunitárias de Origem (TCOs) contribuindo, portanto, para o diálogo, resolução de conflitos e promoção dos direitos indígenas em âmbito nacional, além da promoção do desenvolvimento sustentável que contemple a identidade cultural desses povos.

Para que esse processo se concretize, um dos projetos da CIDOB consiste na criação de uma rede de informações atualizadas sobre as TCOs e os conflitos e negociações decorrentes do processo de titulações e aproveitamento de recursos naturais. 
A CIDOB possui ainda Centros de Computação (CC), de Documentação (CENDIC) e de Planejamento Territorial Indígena (CPTI) apoiados por equipes técnicas.

Desta forma, a Confederação afirma que, através da manutenção de uma Base de Dados atualizada, as organizações terão ao seu alcance, através da Internet, informações importantes sobre "como los actores del proceso, en el ámbito nacional e internacional, de manera que se pueda hacer seguimiento y ejercer presión social sobre las instancias correspondientes en apoyo a las demandas indígenas" (CIDOB 2011).

Para a CIDOB, as organizações beneficiadas pelas informações são as organizações indígenas; de cooperação, como instituições de direitos humanos e de apoio aos direitos indígenas; organismos multilaterais, bilaterais; governamentais e privados, além da imprensa nacional e internacional.

De uma forma geral, pode-se afirmar que o movimento indígena, apesar de congregar diversos atores e reivindicar uma heterogeneidade étnica como um valor, constitui-se como identidade coletiva, que se manifesta principalmente na demanda do reconhecimento legal de seus territórios (ARGANDEÑA 2004, p. 11).

Segundo Argandeña, a formação do movimento indígena na Bolívia é um processo de construção de um discurso segundo o qual vão se comprometendo diversos povos indígenas, ONGs e pessoas, pois mesmo que os diferentes discursos das lideranças do movimento defendam uma permanente autonomia e independência principalmente em relação aos partidos políticos, torna-se praticamente inquestionável que a rede de organizações que acompanham e se envolvem neste processo também estendam sua influência e ação nas seguintes instâncias:

al campo de las definiciones de sentidos y valores, como parte de un universo político que se construye y se propone como alternativo frente a ciertos contenidos de la cultura política del Estado. Por ejemplo, la demanda de "territorio indígena" no sólo representa la principal demanda "material" expresada al gobierno nacional sino también viene acompañada de una definición que articula aspectos como autogobierno y organización política, nunca antes tomados en cuenta por el Estado en alguna forma de ocupación territorial o propiedad de la tierra. O sea se proponen una serie de metas que corresponden al ámbito de logros simbólicos como al campo de los universos políticos. Por tanto es además una lucha por la reapropiación de la historia y por la sustitución de significaciones. (ARGANDEÑA 2004, 11)

Porém, cabe ressaltar que os indígenas da Região Amazônica, integrados na CIBOD, carecem da mesma tradição organizativa que os demais indígenas do ocidente boliviano têm demonstrado ao longo da história do país.

Embora contem com o apoio político e financeiro de ONGs e com uma conjuntura internacional e nacional favorável a seus interesses, como as suas reivindicações e formas de luta são menos radicais que a dos demais indígenas do país, o governo acaba incorporando suas necessidades com mais facilidade nas políticas oficiais.

Este fato acaba dificultando a articulação destes povos indígenas amazônicos a outros setores indígenas do país (ESCÁRZAGA 2004, p. 119).

Em 2008, foi realizado um encontro na cidade de Santa Cruz de la Sierra, intitulado "IIRSA: ENERGÍA, TRANSPORTE Y PUEBLOS INDÍGENAS”. Esse Encontro, patrocinado pela CIDOB, dentre outras ONGs, teve como finalidade discutir os impactos produzidos principalmente pelas obras do Complexo do Rio Madeira na Amazônia boliviana, notadamente em terras indígenas da Região.

$\mathrm{Na}$ Ata do Encontro, ficou registrado o descontentamento das comunidades indígenas afetadas pelas obras do Complexo conforme é demonstrado a seguir:

Los 34 pueblos indígenas de Tierras Bajas de CIDOB manifiestan categóricamente su RECHAZO al Proyecto del Complejo del Rio Madera, de la Hidroeléctrica y la Hidrovía, por resultar atentatorio a la calidad de vida de los pueblos indígenas, al equilibrio de los frágiles ecosistemas del Subandino, el Pie de Monte, las Llanuras y el Bosque Permanente de Pando que serían directamente afectados. (CIDOB 2008, p.1) 
Também ficou expresso no documento o receio da fragmentação dos territórios indígenas e a falta de comunicação dos mesmos com as respectivas capitais dos Departamentos envolvidos:

Exigimos al Presidente de la República que por medio de sus Ministros se pueda determinar un nuevo diseño del Proyecto del Corredor Norte con características de transporte nacional, evite el excesivo endeudamiento nacional, el cambio de trazo para evitar la fragmentación de los territorios indígenas y que permita la conexión de las comunidades con las capitales de departamentos (...) Crear una instancia nacional del Estado que institucionalice la participación directa y activa de los pueblos indígenas y otros sectores sociales en las decisiones de la Gestión Socioambiental de Carreteras. (CIDOB 2008, p.1)

Outro compromisso assumido pela CIDOB na ocasião foi a capacitação técnica de seus membros: "la CIDOB debe promover, en coordinación de sus organizaciones regionales, la capacitación de sus líderes comunales en la temática del Corredor Norte y la Hidroeléctrica del Rio Madera para fortalecer la capacidad de nuestras organizaciones locales (CIDOB 2008, p.1)".

Esta preocupação ocorre devido à percepção de que os impactos socioambientais gerados pela IIRSA afetam invariavelmente as populações mais vulneráveis, no caso as populações indígenas, que não têm a oportunidade de reivindicar reparação de danos sem enfrentar processos desequilibrados de negociações.

Estes processos têm por principal objetivo silenciar os possíveis protestos, mesmo havendo atualmente movimentos, redes, organizações e comunidades que já manifestaram sua oposição ao projeto das hidrelétricas no Rio Madeira.

Cabe destacar que não tem sido considerado o procedimento de consulta aos povos indígenas afetados pelos megaprojetos, em conformidade com as normas internacionais como a Convenção 169 sobre Povos Indígenas e Tribais da Organização Internacional do Trabalho - (OIT) - das Nações Unidas (1989).

Percebe-se então, que a desconstrução da racionalidade capitalista passa a requerer a construção de outra racionalidade social, realizada por novos atores sociais, que vêm se destacando no cenário político, pois "dos conflitos que nascem da racionalidade social dominante emergem movimentos sociais caracterizados por suas novas demandas, formas de organização e estratégias de luta" (LEFF 2001, p. 104), trazendo novos horizontes para as formas de luta pelo poder.

Desta maneira, os movimentos sociais, como os realizados pelas populações indígenas da Amazônia boliviana, que surgem mobilizados por um conceito de racionalidade ambiental, poderão encontrar a orientação de suas ações e de suas estratégias políticas.

Em novembro de 2010, os 34 povos indígenas do Oriente, Chaco e da Amazônia boliviana, componentes da CIDOB, realizaram a XV Grande Assembléia Nacional dos Povos Indígenas na cidade de Santa Cruz, na Bolívia. Nessa ocasião, emitiram uma Resolução onde reafirmaram e condenaram os procedimentos das instâncias encarregadas de levar adiante o processo de Consulta Prévia Livre e Informada sobre o projeto hidrelétrico de Cachuela Esperanza, já que esse projeto não havia sido ainda apreciado pelo movimento indígena, como demonstra o texto a seguir:

el mismo que es parte del IIRSA, proyecto que no fue minimamente consesuado com el movimiento indígena Nacional ni Regional y mucho menos com las autoridades y pueblos de los territórios afectados directa ou indirectamente, por tanto los afectados nos sentimos obligados a tomar las medidas que veamos necesarias para hacer respetar nuestros derechos establecidos em la normativa nacional e internacional. (CIDOB 2010, p.1).

Assim, o movimento indígena da Bolívia cumpre uma importante função ao propor um novo paradigma a respeito de crenças e valores na cultura política do país, pois através de suas ações, os indígenas ressaltam valores e principios básicos de uma sociedade que se quer moderna e democrática. 


\section{CONSIDERAÇÕES FINAIS}

O processo de globalização, expresso em projetos neoliberais como a IIRSA, coloca as populações indígenas, muitas vezes subestimadas como sujeitos sociais, e seu importante importante patrimônio (extensos territórios, biodiversidade, depósito de minerais e conhecimentos tradicionais) em posição de destaque no conflito de interesses que envolve uma grande parcela da população mundial.

O movimiento indígena da Bolívia coloca-se na vanguarda dos movimentos sociais ao demonstrar para os demais movimentos da Região, um exemplo para uma ação organizada e solidária.

Diversos serão os conflitos socioambientais transfronteiriços gerados pela IIRSA nas obras do Complexo Rio Madeira: inundações das terras de cultivo, dos bosques de castanha, dos pastos e de parte da própria floresta, rica em recursos fitogenéticos; havendo ainda uma grande perda da biodiversidade local, tão necessária à sobrevivência das populações locais, notadamente as indígenas.

Devido às particularidades físicas, ecológicas, sociais e étnicas da área afetada pelo Complexo, essa região requer uma legislação particular destinada a estabelecer uma política de convivência pacífica com as diversas comunidades que ali vivem e com o meio ambiente. Infelizmente, verifica-se que a IIRSA objetiva somente a integração física e não a integração de povos e culturas diferentes.

Contribuir para a prevenção e solução de problemas e conflitos socioambientais; fiscalizar o cumprimento da legislação vigente por parte do Estado e dos agentes econômicos; promover alternativas sustentáveis para a utilização dos recursos naturais e, finalmente, apoiar o fortalecimento de movimentos sociais e organizações como a CIDOB para o acesso e a gestão dos recursos naturais, são ações necessárias que devem contar com a contribuição dos centros de pesquisa e tecnologia; do movimento ambientalista e de redes temáticas, visando a capacitação técnica dos atores envolvidos; a promoção do intercâmbio de informações; a difusão de experiências e a coordenação de ações para a proteção socioambiental.

\section{REFERÊNCIAS BIBLIOGRÁFICAS}

AMIGOS DA TERRA-ECOA. O maior tributário do Amazonas ameaçado. S.l.: agosto de 2007. 22 p.

ARGANDEÑA, Wilder M. Molina. Cultura política y nuevas formas de organización y liderazgo en los pueblos indígenas del Beni. Seminario Internacional "Liderazgo, Educación y Fuerzas Armadas: Desafíos y Oportunidades". La Paz, Bolivia: 13-15 de septiembre de 2004. pp.1-11.

BANK INFORMATION CENTER-BIC. Complejo hidroeléctrico del río Madeira. 2009. 3 p. Disponível em: < http://www.bicusa.org/es/Project.10138.aspx >. Acesso em: 20 de março de 2010.

BECKER, Bertha K. Geopolítica da Amazônia. Estud. av. 2005, vol. 19, no. 53. pp. 71-86. Disponível em: $<$ http://www.scielo.br/scielo.php?>. Acesso em: 20 de julho de 2008.

CAVALCANTE, Maria Madalena de A. et all. Políticas Territoriais e Mobilidade Populacional na Amazônia: Estudo sobre as Hidrelétricas de Jirau e Santo Antônio no Rio Madeira/ Rondônia/Brasil. In: XVI Encontro Nacional de Estudos Populacionais. Caxambú: ABEP, 2008. pp. 3-18.

CECEÑA, Ana Esther, AGUILAR, Paula, MOTTO, Carlos. Territorialidad de la dominación. Integración de la Infraestructura Regional Sudamericana (IIRSA). Buenos Aires: Observatorio Latinoamericano de Geopolítica, 2007. 60 p.

CIDOB. Acta de Taller IIRSA: energía, transporte y pueblos indígenas. Santa Cruz de la Sierra, 03 jul. 2008. Disponível em: < http://www.cidob-bo.org/>. Acesso em: 30 jun. 2010.

CIDOB. Confederación de Pueblos Indígenas de Bolivia. [2011] Disponível em: < http://www.cidob-bo. org/>. Acesso em: 12 jan. 2011.

CIDOB. Resolucion de la XV Gran Asamblea Nacional de Los Pueblos Indígenas. Los 34 Pueblos Indígenas del Oriente, Chaco y Amazonia a través de sus 12 Regionales. Santa Cruz: 25 nov. 2010. 3 p. Disponível em: < http://www.cidob-bo.org/>. Acesso em 12 jan. 2011.

CINGOLANI, Pablo. Amazonía Blues. 2010. La Paz, Bolívia: FOBOMADE, 2010. pp. 1-210. 
ESCÁRZAGA, Fabiola. La emergencia indígena contra el neoliberalismo. Politica y Cultura, México: 2004, no 22, pp. 101-121.

FOBOMADE. Hidroeléctrica Jirau en el río Madera un desarrollo no sostenible. Disponível em: $<\mathrm{http}: / /$ www.fobomade.org.bo/ >. Acesso em 12 de março de 2010.

IIRSA. Iniciativa para la Integracion de la Infraestructura Regional Suramericana. Disponível em: $<\mathrm{http}$ ://www.iirsa.org/> Acesso em: 08 de junho de 2009.

JACOBI, Pedro. Meio ambiente e redes sociais: dimensões intersetoriais e complexidade na articulação de práticas coletivas. São Paulo, s.d. 34 p. Disponível em: $<$ http://www.projetosintonia.com/artigos/rapartigopj2000.doc>. Acesso em: 20 jan. 2009.

LEFF, Henrique. Saber Ambiental: sustentabilidade, racionalidade, complexidade, poder. Petrópolis, RJ: Vozes, 2001. $343 \mathrm{p}$.

LEFF, Henrique. Epistemologia Ambiental. São Paulo: Cortez, 2007. 239 p.

MARTÍNEZ ALIER, Joan. O ecologismo dos pobres: conflitos ambientais e linguagens de valoração. São Paulo: Contexto, 2007. 383 p.

McELHINNY, Vince. Reunión de IIRSA-CCT sobre infraestructura y la Amazonia: El futuro de IIRSA em Duda. Washington DC: Biceca, 29 set. 2008. Disponível em: < http://www.biceca.org/es/Article.920. aspx>. Acesso em: 06 nov. 2008.

PAZ, Luciana Leal da. Hidrelétricas e Terras Indígenas na Amazônia: Desenvolvimento Sustentável? [tese]. Rio de Janeiro: Universidade Federal do Rio de Janeiro, 2006. 243p.

THERY, Hervé. Situações da Amazônia no Brasil e no continente. Estud. av. 2005, vol. 19, no. 53 [cited 2008-08-16], pp. 37-49. Disponível em: <http://www.scielo.br/scielo.php?>. Acesso em: 20 jul. 2008.

URUGUAY SUSTENTABLE-REDES. IIRSA. Otro paso em la explotación de los pueblos y territórios sudamericanos. Montevideo: Uruguay Sustentable-Redes-AT, 2006.

VERDUM, Ricardo. Infra-estrutura e políticas territoriais do Brasil no contexto da integração sul. ADITAL, 21 nov. 2007. Disponível em: < http://www.adital.com.br>. Acesso em: 14 jan.2009.

ZIGLIO, Luciana. Cooperação internacional de atores não-estatais. Diez años de cambios en el mundo, en la Geografía y en las Ciencias Sociales, 1999-2008. Actas del X Coloquio Internacional de Geocrítica, Universidad de Barcelona, 26-30 de mayo de 2008. Disponível em: $<$ http://www.ub.es/geocrit/-xcol/57. htm>. Acesso em: 20 jun. 2010. 